\title{
Effect of tool geometry and welding speed on mechanical properties of dissimilar AA2198-AA2024 FSWed joint
}

\author{
Mahdi Masoumi Khalilabad ${ }^{a, *}$, Yasser Zedan ${ }^{a}$, Damien Texier ${ }^{a, b}$, Mohammad Jahazi $^{a}$, \\ Philippe Bocher ${ }^{\mathrm{a}}$
}

a Mechanical Engineering Department, Ecole de technologie superieure (ETS), 1100 Rue Notre-Dame Ouest, Montreal, H3C1K3 Quebec, Canada

${ }^{\mathrm{b}}$ Clement Ader Institute (ICA), University of Toulouse, CNRS, IMT Mines Albi, INSA, ISAE-SUPAERO, UPS, Campus Jarlard, F-81013 Albi, France

\author{
Keywords: \\ Friction stir welding \\ FSW tool design \\ Al-Li alloys \\ Welding speed \\ 2024 aluminum alloy \\ Tensile properties \\ DIC
}

\begin{abstract}
A B S T R A C T
Different tool geometries were used to investigate the joining of aluminum alloys (AA2198 to AA2024) by friction stir welding (FSW). Three shoulder profiles (flat, raised spiral, and raised fan) and five different pin profiles (cone, half threaded cylindrical, straight cylindrical, tapered cylindrical and square) were selected. Preliminary investigations were conducted by moving the tool into a seamless sheet made of the AA2024-T3 in order to select the tools that produce defect-free joints. Preliminary investigations showed the raised fan shoulder profile helps the material flow from the edge of shoulder to the pin creating a smooth surface finish with no flash in comparison with flat and raised spiral shoulder profiles. Pins with a minimum diameter equal to half the plate thickness produced lack of penetration (LOP) defects, while increasing minimum pin diameter to the plate thickness eliminates the LOP defects. Half threaded cylindrical pin produced tunneling defect, whereas defect free joint made by straight cylindrical, tapered cylindrical and cubic pin profiles. So they were selected for joining AA2024 to AA2198. Fracture locations of different joint variants were observed the vicinity of the thermomechanical affected zone (TMAZ) of AA2198-T3 alloy, and in the nugget on the AA2198-T3 side which have the minimum hardness and highest strain localization as confirmed by hardness maps and digital image coronation (DIC). Higher measured temperature than dissolution temperature of AA2198 main strengthening precipitates could be the reason of low hardness and fracture in TMAZ and center of nugget. Furthermore a raised fan shoulder with a tapered cylindrical pin produced highest elongation and yield strength and it was selected as the best candidate for optimization of the welding parameters. It was found that higher rotational and traverse speeds enhance the formation of tunneling and kissing bond defects, suggesting that longer pins have to be used for higher traverse speeds. Welding speed $750 \mathrm{rpm}$ with $450 \mathrm{~mm} \mathrm{~min}{ }^{-1}$ could create joint with highest yield strength.
\end{abstract}

\section{Introduction}

Friction Stir Welding (FSW) is an emerging solid state joining technology that has been successfully used in the aerospace industry as an alternative to riveting for the assembly of airplane fuselage panels made of conventional AA2xxx and AA7xxx alloys [1-3]. The specific properties of structural materials, i.e. the ratio of the selected mechanical property to the material density, constitute one of the main drivers in material selection in the aerospace industry. The addition of one weight percent of lithium to aluminum alloys has been shown in the literature to decrease the density by about $3 \%$ and increase the Young's modulus by $6 \%$, leading to a substantial increase of the specific Young modulus $(E / \rho)$ [4]. These benefits after extensive researches led to the successful development and commercialization of the 3rd generation Al-Li alloys (e.g., AA2198), which have excellent combinations of specific properties, as compared to their conventional counterparts (e.g., AA2024) [5].

Aerospace industry is interested to replace conventional aluminum alloys with new generation of Al-Li alloys for mass gain purpose. Nevertheless, Al-Li alloys still remain relatively expensive. An economical weight reduction solution for structural components involves using hybrid designs with AA2198 alloys for critical regions, and keeping the remaining regions of the structure in AA2024. Thus, joining of aluminum alloys to $\mathrm{Al}-\mathrm{Li}$ alloys appears as a necessity. However, there are relatively few papers on this specific joint, and particularly on optimum conditions for obtaining sound dissimilar FSW joints.

Tunneling defect, flash and kissing bond are common defects of FSWed joint. It is reported that kissing bond decreases the fatigue life

* Corresponding author

E-mail address: mahdi.masoumi-khalilabad.1@etsmtl.net (M. Masoumi Khalilabad). 
time [6]. While, it does not affect significantly the tensile strength $[7,8]$. The key to producing reliable joints by the FSW process is to concurrently select the optimum welding tool and process parameters [9]. Shoulder profile affects the material flow [10], and its optimum design is critical for producing defect-free joints. Some studies have reported either shoulder profile [11-13] or pin design [14-20] effect on the mechanical properties of FSWed joints. Flat shoulder profile with conical pin is the simplest design and has been used successfully for joining aluminum alloys [21,22]. Also, adding a step to a conical pin [23] and half screwed pin (in comparison to full screwed) [24] was shown to increase the joint mechanical properties and to eliminate the cavity defect. The weld prepared by square pin profile results in smaller grain size and higher mechanical properties $[18,25]$. They were reported to produce defect free joints, irrespective of welding speeds [26]. As mentioned, appropriate process parameters have an important role to produce a sound weld. A low rotational speed or a higher traverse speed cause tunneling defect and kissing bond due to insufficient material mixing as the heat input is too low and the material is not soft enough [27]. On the other hand, a combination of high speeds and high traverse speeds causes cavities due to abnormal stirring [28]. In the range of optimized welding parameters, increasing the traverse speed in the presence of a constant rotational speed improves joint mechanical properties [29], while increasing the rotational speed results in higher heat input and lower mechanical properties [30]. It should be noted that close to the solidus temperature of the material, the rotational speed has negligible effect on mechanical properties due to self-stabilizing phenomenon $[31,32]$.

The FSW parameters were optimized for several dissimilar joints between AA2024 to 5xxx series [33], 6xxx series [34,35] and 7xxx series [36]. Dissimilar friction stir welding of AA2024-T3 and AA2198$\mathrm{T} 3$ in butt-joint configuration has been already investigated in terms of microstructural and specific mechanical characterizations for a particular configuration $[37,38]$, but no research on optimization of friction stir welding tool geometry and parameters for joining dissimilar AA2024 and AA2198 joints has been reported in the open literature. Optimized welding parameters for producing similar butt joints for each alloy, AA2024-T3 and AA2198-T3, have been proposed in the literature [2,39-42]. The optimized rotational speeds are actually close for both alloys in the thickness less than $10 \mathrm{~mm}$, while the optimized traverse speed for AA2024 is yet lower $\left(73 \mathrm{~mm} \mathrm{~min}^{-1}\right.$ vs. $300 \mathrm{~mm} \mathrm{~min}^{-1}$ ). Therefore, a trade-off in terms of welding parameters must be found for the welding of AA2024 to AA2198.

In this study, the effect of the shoulder geometry and pin profile on the microstructure and mechanical properties of FSWed AA2024-T3/ AA2198-T3 joints is documented. To that end, three different shoulder and five pin geometries were used to produce a FSW pass in an AA2024 plate for a given set of welding parameters. Macrograph observations were done to evaluate the occurrence of defects such as tunneling, kissing bond, and flash. Tensile properties (yield strength, ultimate tensile strength, and ductility) of the different welds were investigated to understand the effect of tool geometry and select an optimal tool design. To assess the influence of FSW welding speed on the mechanical properties of the joints, different traverse speeds in the range of $50-450 \mathrm{~mm} \mathrm{~min}^{-1}$ with two different rotational speeds, 750 and $1000 \mathrm{rpm}$, were investigated with the optimal tool. Fractographic analyses in combination with microhardness maps and Digital Image Correlation (DIC) technique were used to investigate microstructural features responsible for the fracture.

\section{Experimental procedures, materials and methods}

\subsection{Base materials}

Base materials consisting of AA2024-T3 and AA2198-T3 rolled sheets with a thickness of $3.2 \mathrm{~mm}$ were used. The nominal chemical compositions of these base materials are reported in Table 1.

\subsection{Tools and fixture designs}

A specific fixture was designed to increase the repeatability rate of the friction stir welding process, as shown in Fig. 1. The welding direction, the cross-weld direction and the normal direction are denoted WD, CWD and ND, respectively. Stoppers, supporters, and clamps were used to fix the plates in these directions, respectively. Clamps and supporters are equipped with screws, and so they apply opposite forces to the ND and CWD directions, while there is no need to apply any force in the welding direction due to the application of the welding force. The supporters and clamps were fixed with a torque wrench to ensure that reproducible forces were applied during the different welding tests.

Seven tool designs, denoted from A to G in Fig. 2, were designed and manufactured based on literature recommendation. The formulas for calculating the specific tool dimensions are shown in Table 2. AISI 4340 steel hardened up to $49 \mathrm{HRC}$ by quenching and tempering before machining was selected for the tool material, as recommended by Ref. [45].

\subsection{Welding process}

The first step in the present study was to find the appropriate tool geometry for friction stir welding of AA2024-T3 and AA2198-T3. Two series of welds were produced and investigated. The first of these series were made by moving the tool into a seamless one piece of the AA2024T3 sheet (i.e., bead-on-plate weld) in order to select the tools that produce defect-free joints on the basis of metallography and visual examinations. The second series was produced using dissimilar welding of AA2024-T3 and AA2198-T3 plates. Then, the tool that could produce a joint between AA2024 and AA2198 with the highest yield strength was selected as the best candidate for further optimization. To optimize the welding for the selected tool, combinations of traverse $(\nu)$ and rotational speeds $(\omega)$ used in the present study and their related sample codes are presented in Table 3 with heat input index $[47,48]$ which is a candidate for the representation of the average thermal profile during welding. The rotation speed, the welding traverse speed, the plunge depth and the tilt angle were $750 \mathrm{rpm}, 50 \mathrm{~mm} \mathrm{~min}^{-1}, 0.2 \mathrm{~mm}$, and $0^{\circ}$, respectively. Sodium hydroxide solution $\left(20 \mathrm{~g} \mathrm{NaOH}+100 \mathrm{~mL} \mathrm{H}_{2} \mathrm{O}\right)$ was used in order to remove the material stuck to the tools between experiments. For the dissimilar configuration, AA2024 plates were placed on the retreating side (RS), with the weld direction perpendicular to the transverse direction (TD), and on the advancing side (AS), AA2198 plates were placed with their rolling direction (RD) perpendicular to the welding direction. This configuration was chosen because the tensile properties of AA2024-T3 in transverse direction are comparable with those of AA2198-T3 in the rolling direction [38]. Consequently, this configuration could maximize the joint efficiency in the tension condition.

\subsection{Sample preparation and mechanical tests}

The FSWed samples were prepared for metallographic observations using standard polishing procedures down to $1 \mu \mathrm{m}$ diamond paste followed by BUEHLER Vibromet polishing for $48 \mathrm{~h}$, with a $0.05 \mu \mathrm{m}$ colloidal silica solution. A Keller etchant was employed for $15 \mathrm{~s}$ to reveal the microstructure. Optical micrographs were obtained with an OLYMPUS Lext OLS4100 laser scanning confocal microscope. Tensile test samples for base metals were done on TD and RD directions for AA2024 and AA2198, respectively. Tensile specimens were machined from the welded plates such that the loading direction was parallel to the cross-welding direction of the joined plates. Specimens were extracted from both base materials to provide a reference, and from the joints, as specified in Fig. 3a (the joint being centered in the specimen gage). Tensile tests were performed on dog-bone tensile specimens with the geometry displayed in Fig. 3b. As the tool plunging into the material surface produces sharp edges which are stress concentration sites, the 
Table 1

Chemical compositions of AA2024 and AA2198 alloys in wt.\% [43,44].

\begin{tabular}{llllllllll}
\hline Alloy & $\mathrm{Cu}$ & $\mathrm{Li}$ & $\mathrm{Mg}$ & $\mathrm{Ag}$ & $\mathrm{Mn}$ & $\mathrm{Fe}$ & $\mathrm{Zn}$ & $\mathrm{Si}$ & $\mathrm{Tl}$ \\
\hline AA2024 & $3.8-4.9$ & - & $1.2-1.8$ & - & $0.3-0.9$ & $\leqslant 0.5$ & 0.2 \\
$\mathrm{AA2198}$ & $2.9-3.5$ & $0.8-1.1$ & $0.25-0.8$ & $0.1-0.5$ & $\leqslant 0.5$ & $\leqslant 0.01$ & $\leqslant 0.35$ & $\leqslant 0.08$ & - \\
\hline
\end{tabular}

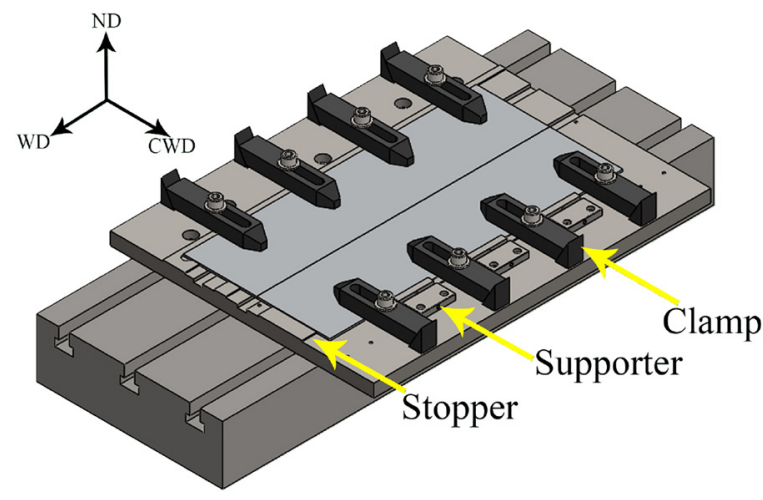

Fig. 1. Fixture designed for the repeatability of the FSWed joints. The welding plates are fixed by stoppers, supporters, and clamps in the directions WD, CWD, and ND respectively.

tensile samples were polished on both sides to remove any possible surface defects including kissing bond. Tensile tests were conducted with a $5 \mathrm{kN}$ Kammrath and Weiss micro-tensile device at a constant crosshead displacement rate of $7 \mu \mathrm{m} \mathrm{s}^{-1}$. The specimen elongation along the loading direction was continuously recorded using a Keyence LS-7030M optical extensometer, measuring the displacement in the region between the two TMAZ regions $\left(L_{0}=16 \mathrm{~mm}\right)$. Tensile tests were repeated three times for each welding condition. In parallel, in-situ optical microscope tensile tests were conducted for different loading conditions to calculate the local strain fields from measured displacement fields via an optical high resolution-digital image correlation technique (OHR-DIC), as explained in Ref. [37]. Optical micrographs were taken in dark field mode with an OLYMPUS DSX-500 optical microscope in an unloaded state to investigate the irreversible deformation of the joints. In order to track the local kinematic field, a surface code was generated at the surface of the sample with the Keller etchant, the so-called speckle. In-plane local displacement fields were assessed for each individual micrograph region with OpenDIC, an open source software application [49]. Strain fields were then calculated with a JAVA companion working with Fiji software based on a twodimensional and iso-parametric finite element formalism, with nodes being the center of the subsets, and with four Gauss bilinear interpolation points per element.

In order to analyze the hardness distribution through a weld crosssection, 31 profiles of 260 indents were made with an increment of $80 \mu \mathrm{m}$ in the CWD and ND, respectively. An automatic microhardness machine (CLEMEX), with a $25 \mathrm{~g}$ load applied for $10 \mathrm{~s}$ was used to obtain
Table 2

Selected dimensions for FSW tool design $(* \mathrm{PT}=$ plate thickness $=3.2 \mathrm{~mm})$.

\begin{tabular}{lllll}
\hline Parameter & Suggested formula & Ref. & $\begin{array}{l}\text { Used value } \\
(\mathrm{mm})\end{array}$ & Types \\
\hline Shoulder diameter & $2.2 \mathrm{PT}+7.3$ & {$[45]$} & 15.8 & All tools \\
Pin length & PT-0.3 & {$[46]$} & 2.7 & All tools \\
Max-pin diameter & PT & {$[23]$} & 3.2 & A, B and C \\
& $0.8 \mathrm{PT}+2.2$ & {$[45]$} & 4.7 & D, E, F and G \\
Min-pin diameter & $0.5 \mathrm{PT}$ & - & 1.6 & A, B and C \\
& PT & - & 3.2 & F
\end{tabular}

Table 3

Welding speed parameters.

\begin{tabular}{llll}
\hline Sample code & Rotational speed & Traverse speed & Heat input index \\
\hline & $(\omega) \mathrm{rpm}$ & $(\nu) \mathrm{mm} \mathrm{min}^{-1}$ & $\frac{\omega^{2}}{\nu} \times 10^{-4}(\mathrm{HI})$ \\
F1 & & 50 & 1.1250 \\
F2 & 750 & 150 & 0.3750 \\
F3 & 750 & 300 & 0.1875 \\
F4 & 750 & 450 & 0.1250 \\
F5 & 750 & 300 & 0.3333 \\
F6 & 1000 & 450 & 0.2222 \\
\hline
\end{tabular}

the Vickers microhardness maps.

\subsection{DSC and temperature measurements}

Differential Scanning Calorimetry (DSC) measurements were carried out by PerkinElmer equipment model pyris 1 . The experiments were conducted under a high purity nitrogen flux. The heating ramp rate was $15 \mathrm{~K} \mathrm{~min}^{-1}$ from 323 to $773 \mathrm{~K}$. We chose to keep at an initial temperature of $323 \mathrm{~K}$ for $10 \mathrm{~min}$ in order to allow enough time for the apparatus to stabilize. The samples are $0.5 \mathrm{~mm}$ thick discs with a diameter of $4 \mathrm{~mm}$, in order to fit in the dedicated pure aluminum crucibles.

To find the maximum temperature experienced by the base metal, K-type thermocouples located on the weld line (edge of the shoulder) at both advancing and retreating sides were used. Thermocouples were placed inside small holes with a diameter of $1 \mathrm{~mm}$ drilled on the surface of base materials. Thermocouples were fixed with Thermigrease TG 20033, which is a silicone-free hard curing paste material known to optimize heat transfer in high temperature conditions. A digital thermometer was used to connect thermocouples to a data acquisition system installed on a personal computer in order to record the

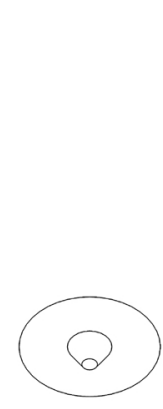

A

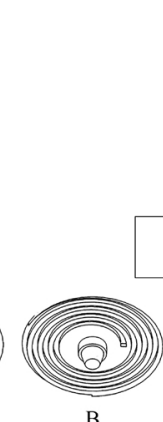

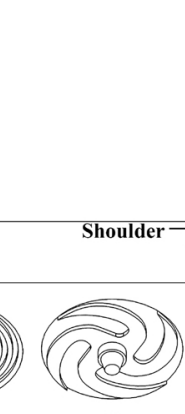

$\mathrm{C}$

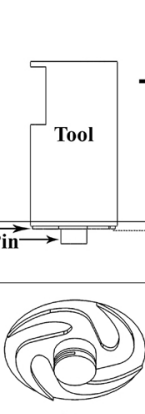

D

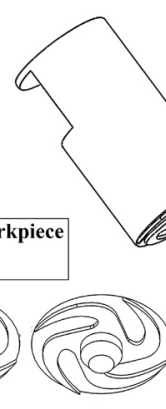

G

Fig. 2. Different tool designs: (A) flat shoulder with conical pin, (B) raised spiral shoulder with stepped conical pin, (C) raised fan shoulder with stepped conical pin, (D) raised fan shoulder with threaded cylindrical pin, (E) raised fan shoulder with cylindrical pin, (F) raised fan shoulder with tapered cylindrical pin, and $(\mathrm{G})$ raised fan shoulder with cubic pin. 


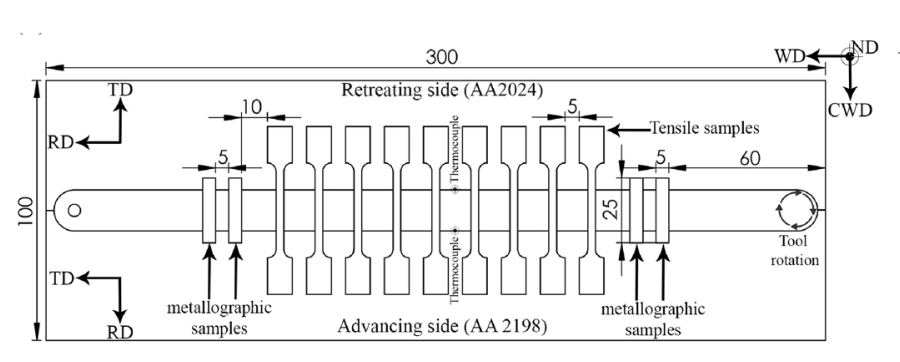

(a)

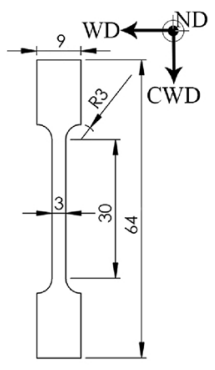

(b)

Fig. 3. Experimental dissimilar friction stir welding process setup: (a) plates size and locations of the samples extraction and (b) geometry of the dog-bone tensile specimens; all the dimensions are in millimeters.

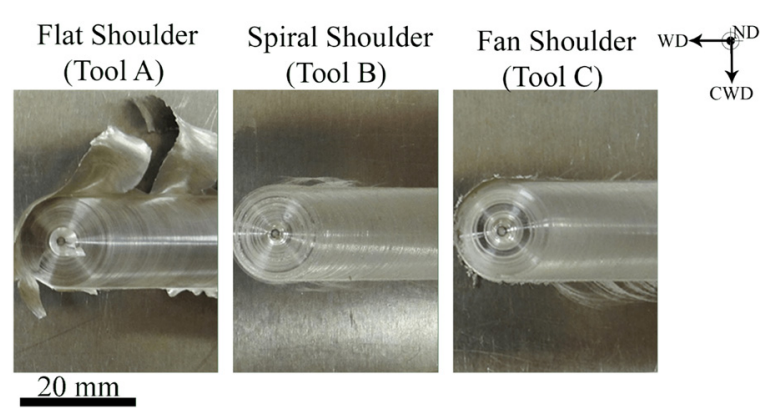

Fig. 4. Surface morphology related to bead on plate of AA2024 material produced by tools A, B, and C. The raised spiral (tool B) and raised fan (tool C) shoulders prevent weld flashes.

\section{Table 4}

Defects produced as a result of tool design related to bead on plate of AA2024. The rotation speed and the welding traverse speed were $750 \mathrm{rpm}$ and $50 \mathrm{~mm} \mathrm{~min}^{-1}$, respectively.

\begin{tabular}{llll}
\hline Tool & Flash defect & LOP defect & Tunneling defect \\
\hline A & Yes & Yes & Yes \\
B & - & Yes & - \\
C & - & Yes & - \\
D & - & - & Yes \\
E, F and G & & Defect free & \\
\hline
\end{tabular}

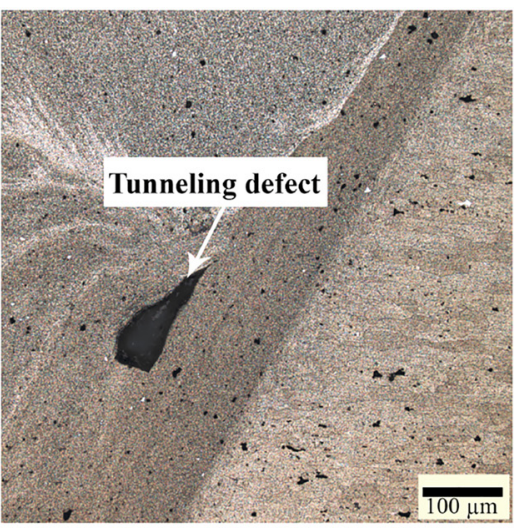

(a)

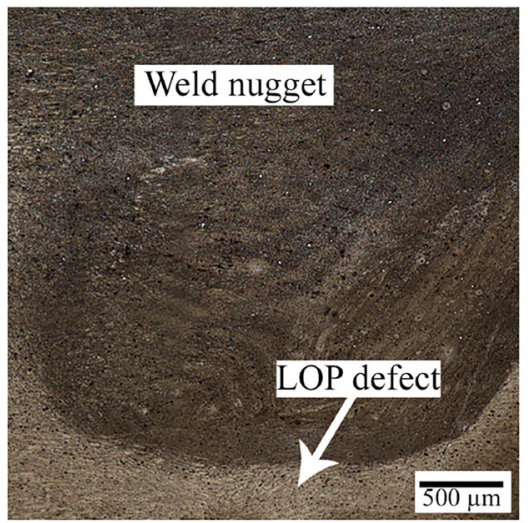

(b) temperature evolution during the FSW process.

\section{Results and discussion}

\subsection{Tool selection for joint between AA2024 and AA2198}

\subsubsection{Defects for bead on plate of AA2024}

The surface pattern resulting from the FSW process with the three different shoulders (flat, spiral and fan) is shown in Fig. 4. The flat shoulder (tool A) tends to produce flash defects on the welded surface as the flat shoulder is not effective for trapping the flowing material under the bottom shoulder [45]. Less flash was observed on the advancing side in comparison to retreating side. On the other hand, the raised spiral (tool B) and raised fan (tool C) shoulders prevent the flash defect formation as their surface features return the material to the center during the rotation of the tool. Thus, both spiral and fan shoulder profiles eliminate the need to tilt the tool for avoiding flash defects. Furthermore, the finishing surface produced by spiral shoulder had some degree of galling while the finishing surface produced by fan shoulder was smooth. The results show raised fan is a better selection for tool shoulder profile.

Metallography and visual examination results corresponding to the occurrence of tunneling defects and a lack of penetration (LOP) for a bead on plate of AA2024 are summarized in Table 4. Examples of LOP and tunneling defects observed for tool A are shown in Fig. 5. Metallographic observations demonstrated that tools with a minimum pin (min-pin) diameter equal to half the plate thickness (such as tools A, B and $\mathrm{C}$ ) produced LOP defects. The pin length should increase for this specific design. When a bigger min-pin diameter was used (equal to the plate thickness), such as in tools D, E, F, and G, no LOP defects were

Fig. 5. Defects produced in the bead-on-plate welds: (a) tunneling defect (tool A, advancing side in the middle), (b) LOP defect (tool A) and (c) without defect (tool E, advancing side). 


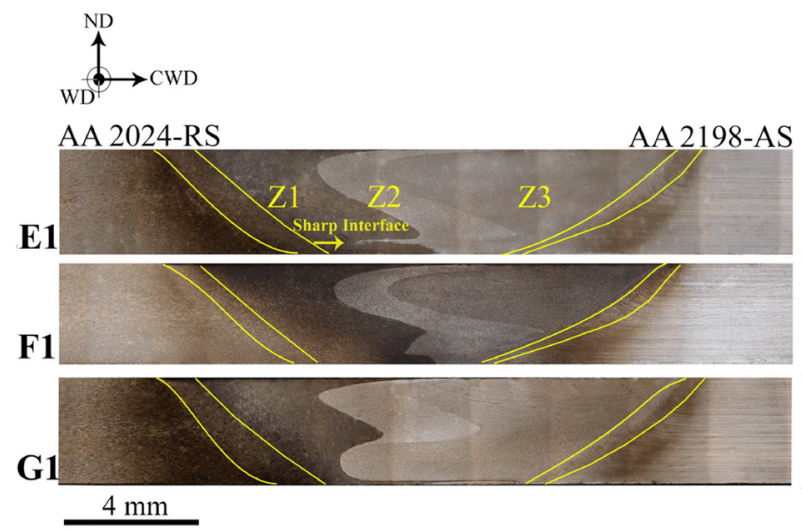

(a)

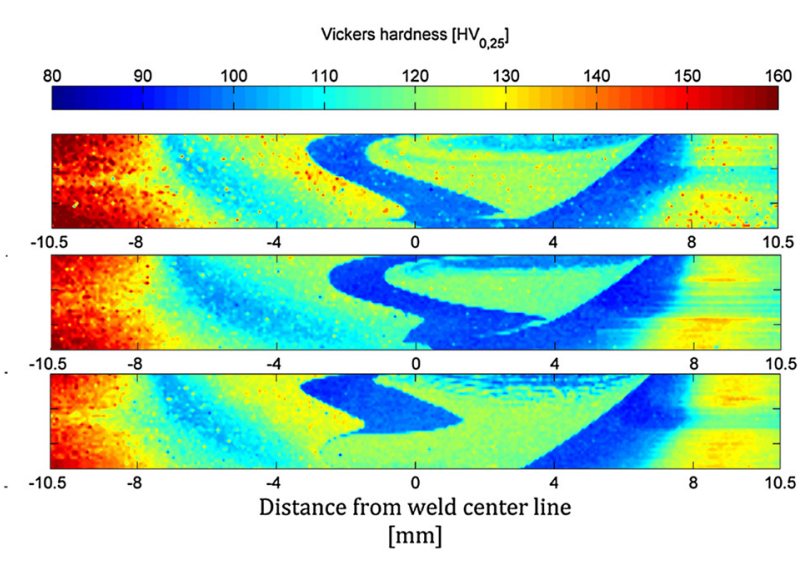

(b)

Fig. 6. Cross-section observations of samples E1, F1, and G1. (a) Nugget region delimited by yellow solid lines on CWD-ND cross-section where the different colors resulting from etching are denoted zones Z1, Z2, and Z3. (b) Corresponding 2D microhardness maps showing the minimal hardness values in Z2 zone, shoulder affected area, and TMAZ/HAZ on AA2198 side.

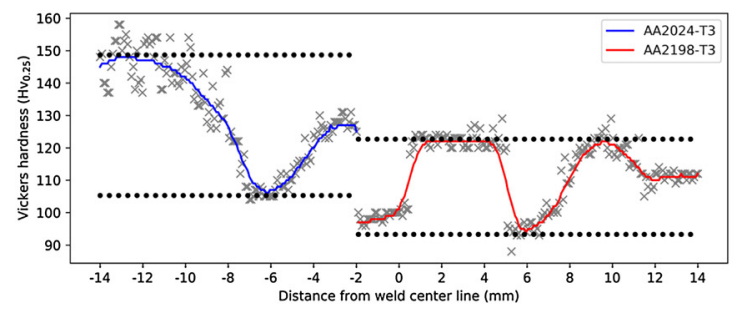

(a)

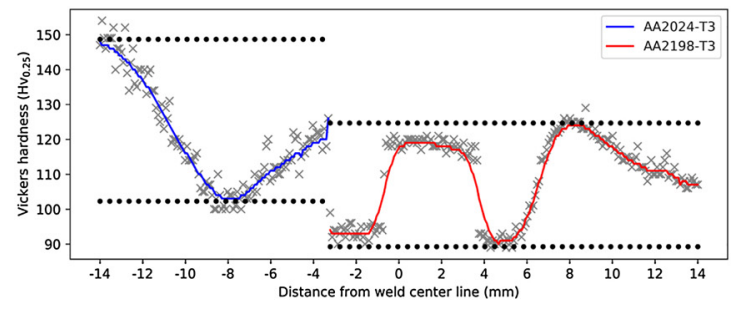

(b)

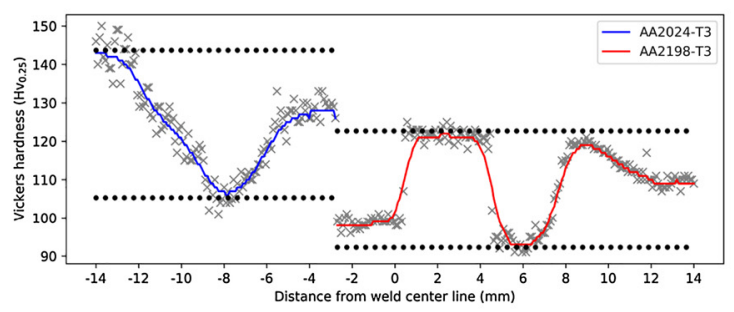

(c)

Fig. 7. Micro-hardness distributions performed at mid-thickness (middle) of different joint variants, (a) sample E1, (b) sample F1 and (c) sample G1.

found, indicating that material flow across the weld centerline had been amplified, ensuring the mixing of the material at the bottom of the weld [50]. Furthermore, the interfacial heat energy generation at the bottom of the joint is a function of the cone diameter, i.e., a higher diameter results in a higher heat input $[51,52]$. The results of the half-threaded cylindrical pin (tool D) indicate the presence of a small tunneling defect, whereas no such defects were found in the straight version (tool E).

\subsubsection{Microstructure and microhardness maps of AA2024 and AA2198 joints}

On the basis of Table 4, only tools E, F and G are capable of producing defect-free beads on plate welds for a set of low welding speeds. They were therefore selected for joining AA2024 to AA2198. The AA2024 and AA2198 joints made by tools E, F, and G were denoted codes E1, F1, and G1, respectively, and their macrograph cross-section observations in planes CWD-ND can be seen in Fig. 6a. The produced joints were free of defects. The three different microstructure zones typically generated by the FSW process, denoted nugget, thermo- mechanically-affected zones (TMAZ), and heat-affected zones (HAZ), as well as the base material, can be identified. Using contrast, grain size, or morphology, the transition between the base metals and the nugget region are straightforward as small recrystallized grain microstructures are found in the nugget region. This transition between the two regions is drawn with a yellow line. Tracking the boundaries between the base metal and HAZ is a challenge. It should be noted from Fig. 6a that the nugget zone of all the joints is composed of three different regions, shown with different colors after etching on the CWD-ND planes. These three zones are denoted Z1, Z2, and Z3. Furthermore, a sharp interface is present for samples E1, whereas the interface of sample $\mathrm{F} 1$ is not irregular due to the presence of a cone. It can be seen locally that the material flow at the bottom of the joint is amplified as the pin diameter is increased, causing a sharp interface [50].

In order to find the weak regions of the joints, microhardness maps were obtained, and the results are presented in Fig. 6b. They show similar patterns to the weld macrographs shown in Fig. 6a. By considering the hardness of the as-received materials 


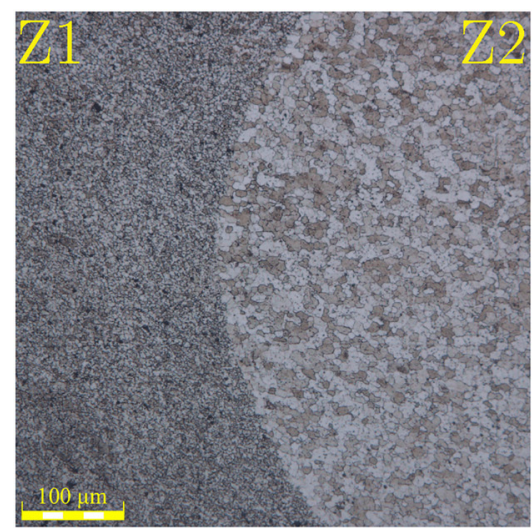

(a)

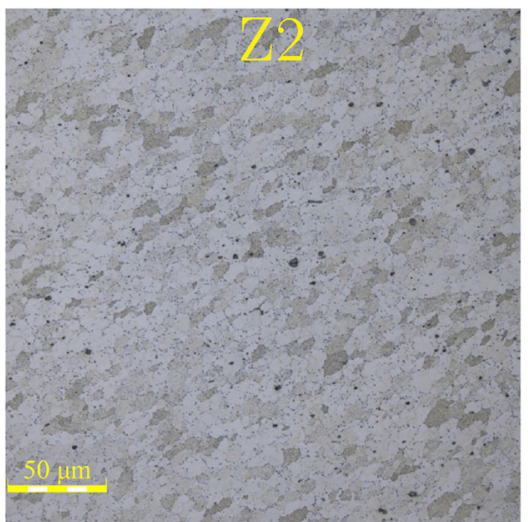

(b)

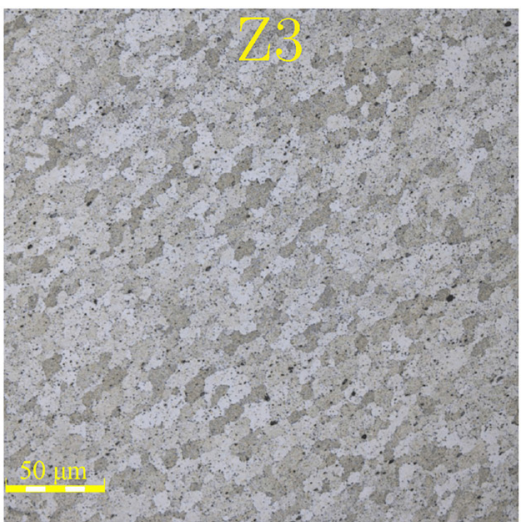

(c)

Fig. 8. Cross-section optical metallography images of samples F1, (a) Z1/Z2 boundary, (b) inside Z2 and (c) inside Z3. Zone Z2 and Z3 have coarser grain sizes than zone $\mathrm{Z1}$, while there is no significant grain size difference between zones $\mathrm{Z} 2$ and $\mathrm{Z3}$.
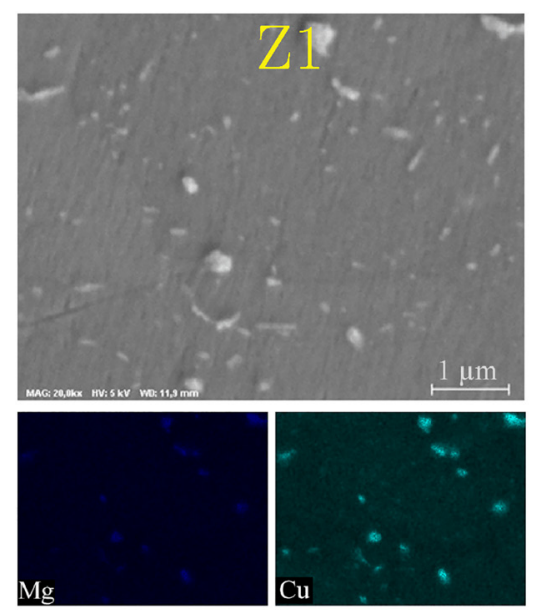

(a)

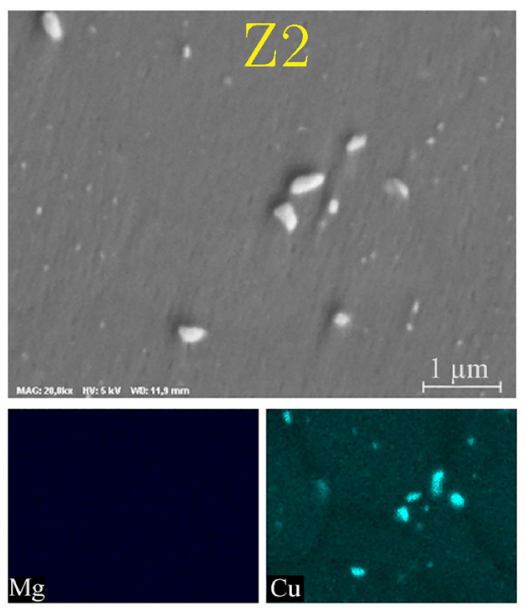

(b)

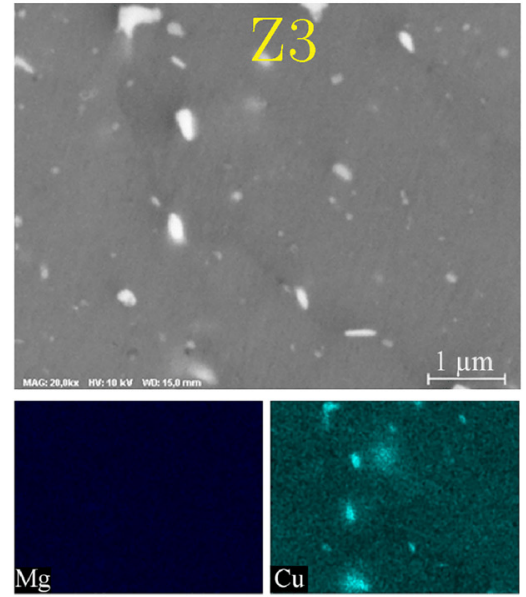

(c)

Fig. 9. SEM micrographs of Z1, Z2 and Z3 zones and the related EDS maps for elements Mg and Cu. (a) Zone Z1, (b) Zone Z2 and (c) Zone Z3. Zone Z1 has different precipitates in comparison with Zone Z2 and Z3.

(AA2024 $\approx 150 \mathrm{HV}_{0.25}$ and $\mathrm{AA} 2198 \approx 125 \mathrm{HV}_{0.25}$ ), it can be seen that Zones $\mathrm{Z} 2$ and TMAZ/HAZ, and the shoulder-affected region (top of the nugget) on the AA2198 side, have the minimum hardness values $\left(90 \mathrm{HV}_{0.25}\right)$, regardless of the pin geometry. Fig. 7 shows the hardness evolution along the joint is different at AA2024 side in comparison to AA2198 side. The hardness of AA2198 drops in the middle of joint and TMAZ/HAZ area; while, the AA2024 hardness drops only in TMAZ/ HAZ area. This trend could be seen in all the joint variants. Furthermore, the TMAZ/HAZ of the retreating side (AA2024) has a higher hardness than the advancing side (AA2198).

To gather more details about the joint heterogeneity, the metallography images with higher magnifications from the Z1/Z2 boundary, inside the $\mathrm{Z} 2$ and $\mathrm{Z} 3$ regions, are shown in Fig. 8. It can be seen that the grains of the AA2198 side (Z2) are coarser than those from the AA2024 side (Z1) in the nugget region (Fig. 8a). The delimitation between both materials in the nugget is very clear. Comparing the microstructure of the $\mathrm{Z} 2$ and $\mathrm{Z3}$ regions in Fig. $8 \mathrm{~b}$ and c shows that there is no significant difference between the grain sizes of the two zones. Furthermore, SEM micrographs and the related EDS maps (Fig. 9) show the presence of $\mathrm{Mg}-\mathrm{Cu}$ precipitates in the $\mathrm{Z1}$ zone and $\mathrm{Cu}$ precipitates in Zones $\mathrm{Z} 2$ and Z3. These precipitates could be $\mathrm{S}\left(\mathrm{Al}_{2} \mathrm{CuMg}\right)$ [53] and $\mathrm{T} 1\left(\mathrm{Al}_{2} \mathrm{CuLi}\right)$ [54] which are the main hardening phase of AA2024 and 2198, respectively. The grain structure and nature of precipitates shows that the joint is not mixed completely and zone Z2 and Z3 are related to the AA2198 material side.

\subsubsection{DSC and temperature measurements}

DSC test on the base metal AA2198-T3 with temperature measurements at the TMAZ of the advancing and retreating sides were performed to help clarify the root cause of the low hardness levels observed in Fig. 6b. It could be seen that the dissolution of GP-zones occurs at low temperatures in the first endothermic peak A in Fig. 10a [55]. The peaks $\mathrm{B}$ and $\mathrm{C}$ indicate the precipitation and thickening of $\mathrm{T} 1\left(\mathrm{Al}_{2} \mathrm{CuLi}\right)$ phase, respectfully [56]. Both of precipitation of $\Theta\left(\mathrm{Al}_{2} \mathrm{Cu}\right)$ and dissolution of $\mathrm{T} 1\left(\mathrm{Al}_{2} \mathrm{CuLi}\right)$ phases concurrently start from Peak D $(640 \mathrm{~K})$ [57]. The maximum measured temperature of the TMAZ (Fig. 12b) on the AA2198 side is higher than the dissolution temperature of $\mathrm{T} 1\left(\mathrm{Al}_{2} \mathrm{CuLi}\right)$ precipitates. Therefore, even if the exposed time is short, the welding process can partially dissolve them in TMAZ region. The temperature is also high enough for precipitate growth in the TMAZ region on the AA2024 side, as already reported by Genevois et al. [58]. Hence, the coarsening of S phase in AA2024 and coarsening/partial dissolution of $\mathrm{T} 1\left(\mathrm{Al}_{2} \mathrm{CuLi}\right)$ precipitates during the FSW process are probably the reasons for the observed lower hardness of the TMAZ areas in Fig. 6b. It shows that the AA2198 material is more sensitive to high temperature exposure. 


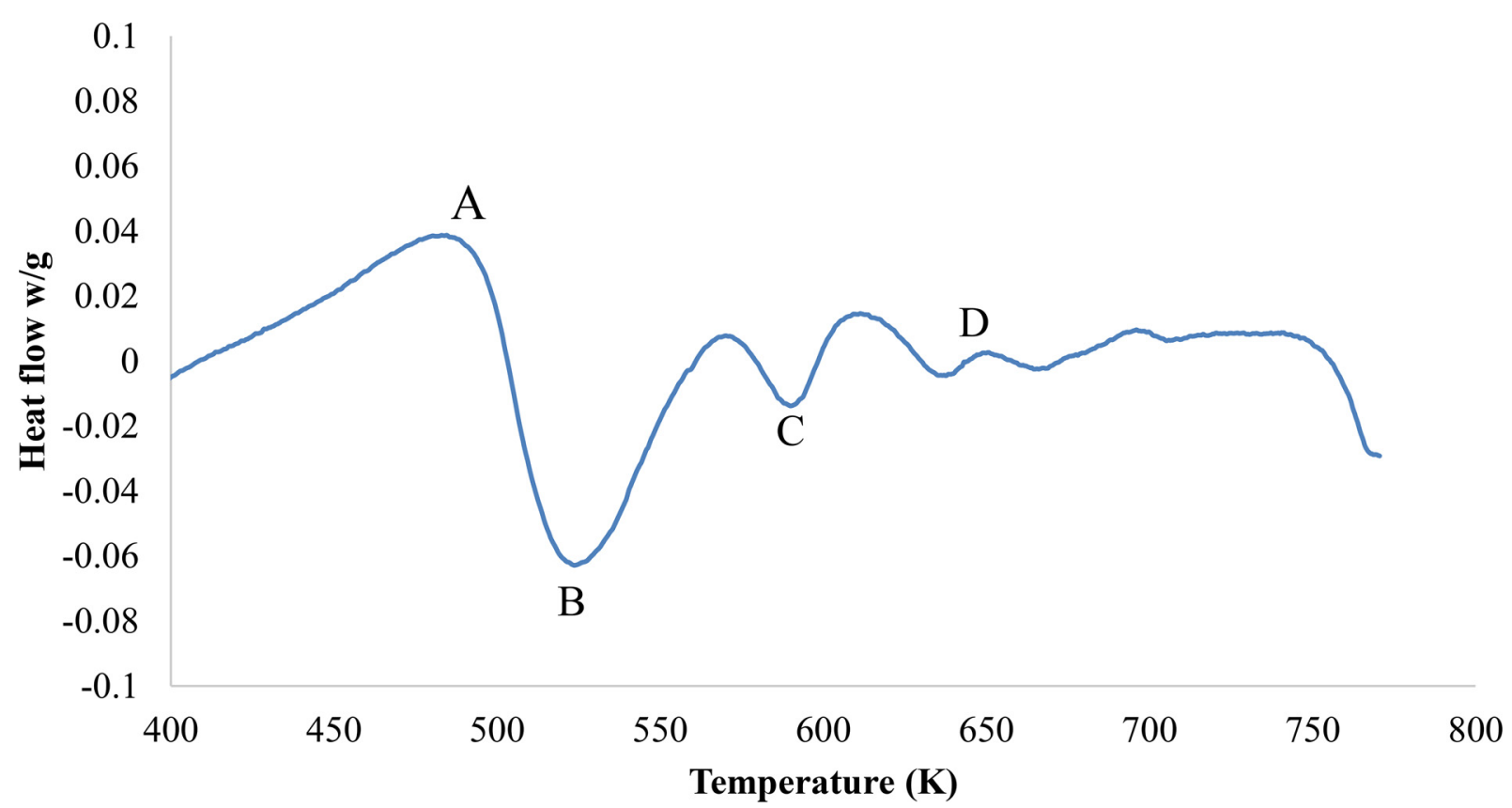

Fig. 10. DSC and temperature measurements, (a) DSC result of base metal AA2198-T3 and (b) temperature measurement of TMAZ on both joint sides.

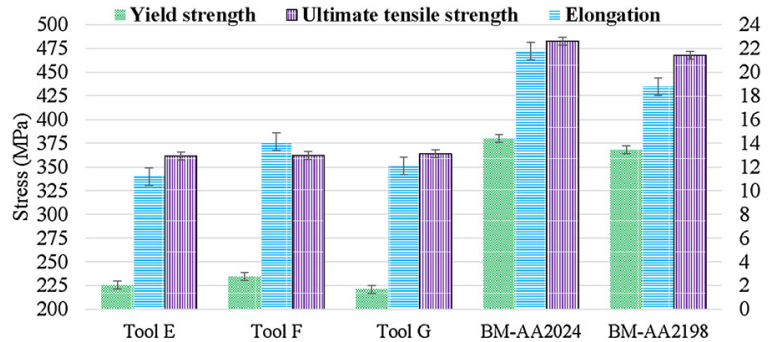

Fig. 11. Mechanical properties of FSW joints produced by tools E, F and G at $750 \mathrm{rpm}$ and $50 \mathrm{~mm} \mathrm{~min}^{-1}$. The joint produced with tool $\mathrm{F}$ demonstrated higher mechanical strength and elongation.

The sound joints produced by tools E, F and, G were evaluated using tensile tests to select the best design. The elongations (A\%), the $0.2 \%$ offset yield strengths (YS) and the ultimate tensile strengths (UTS) of the joints tested in the as-welded condition are shown in Fig. 11. It can be seen that the tensile properties follow the same trend and are similar for all the joints. It is worth noting that the joint produced by tool $\mathrm{F}$ demonstrated both higher yield strength and elongation. The strain localization during the tensile test occurred in TMAZ/HAZ of AA2198 and center of nugget for all joint variants (Fig. 12). Besides, the main strain localization is in the center of nugget for sample F1; while, main strain localization occurred in TMAZ/HAZ of AA2198 for sample E1 and G1. All tensile specimens of samples E1 and G1 failed on the advancing side (AA2198) in the TMAZ. F1 specimens failed simultaneously, at both TMAZ of AA2198 and the middle of the joint (Z2 zone); however, final rupture occurred in the middle of the joint. Both fracture modes are shown in Fig. 13, confirming the results of DIC and microhardness maps that the nugget (zone Z2) and TMAZ of AA2198 are the weak regions of the joints. The tool dynamic volume defined by Ref. [26] could explain the different local mechanical response of tool $\mathrm{F}$. Tool $\mathrm{E}$ and $\mathrm{G}$ have the same dynamic shape and volume which, is bigger than dynamic volume of tool $\mathrm{F}$ (Table 5). Less dynamic volume of tool $\mathrm{F}$ results in less material participating in the joint area and can be the reason of fracture in the middle of the joint.

\subsubsection{Fractography}

Fractography results using SEM obtained after monotonic tensile tests are reported in Fig. 14. The fracture surface in the middle of the joint (Fig. 14a) shows a ductile fracture with the small dimples

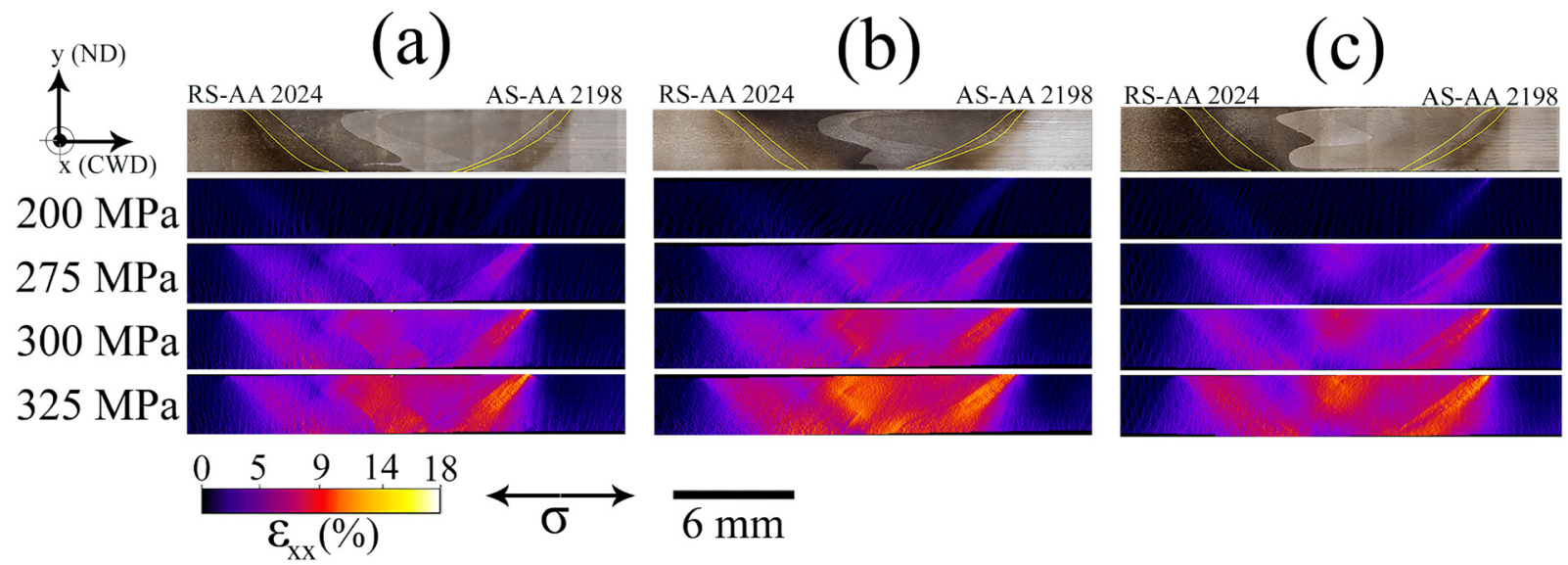

Fig. 12. Local in-plane strain distribution obtained with DIC for joints E1, F1 and G1. The strain localization for all tools are in TMAZ/HAZ of AA2198 and center of nugget. 


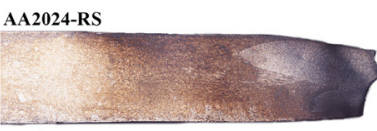

$4 \mathrm{~mm}$

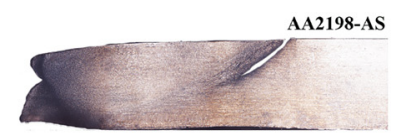

(a)

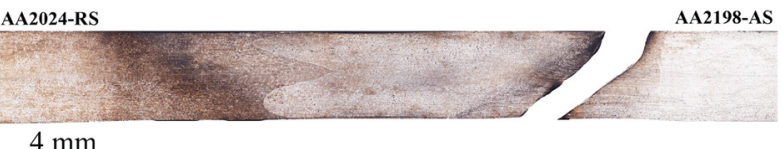

(b)

Fig. 13. Fracture locations after monotonic tensile tests: (a) sample F1, middle of the joint, or (b) sample G1 on the advancing side in the TMAZ. The fracture locations correspond to the locations with the lowest hardness values in Fig. $6 \mathrm{~b}$ and strain localization in Fig. 12.

Table 5

Dynamic volume of tool pins. Tool rotation creates dynamic volume e.g. cubic tool pin transforms to a cylindrical tool pin by rotation.

\begin{tabular}{ll}
\hline Tool code & Dynamic pin volume $\left(\mathrm{mm}^{3}\right)$ \\
\hline Tool E & 47.7 \\
Tool F & 40.0 \\
Tool G & 47.7 \\
\hline
\end{tabular}

(Fig. 14b). On the other hand, fracture surfaces in the TMAZ of AA2198 (Fig. 14c) show a ductile and shear fracture with no evidence of dimples, even at higher magnification, probably suggesting the full dissolution of precipitates in this region of the weld (Fig. 14d).

\subsection{Optimization of welding speed parameters}

The joint produced by tool $\mathrm{F}$ demonstrated slightly better yield strength and elongation. Furthermore, the machining of tool $\mathrm{F}$ is easy and its wear vs. cubic pin is less. Also, it requires less force to penetrate into the material in the beginning of welding vs. straight cylindrical tool. So, tool F was considered as the best tool for further optimization.

\subsubsection{Joint macrograph}

Macrographs obtained on the joints produced with various welding parameters (Table 3) are shown in Fig. 15. It can be seen that increasing the rotational or traverse speed raises the possibility of tunneling defects (sample F6). On the other hand, for all new conditions, kissing bond defects were found in the welds, showing that the mixing conditions were not high enough in temperature at the root of the weld to allow proper material flow. Thus, it can be concluded that the pin length must be increased as the traverse speed increases in order to avoid the formation of kissing bond defect. The tool geometry can still be optimized in the present investigation for higher traverse speed parameters.

\subsubsection{Microhardness map}

Two-dimensional hardness maps across the ND-CWD section for various welding traverse speeds (Fig. 16) revealed that increasing the traverse speed significantly improves the hardness of the joints, in particular, that of the TMAZ. Specifically, the hardness increased by about 16 and $35 \mathrm{HV}_{0.25}$ for AA2198 and AA2024 sides, respectively,

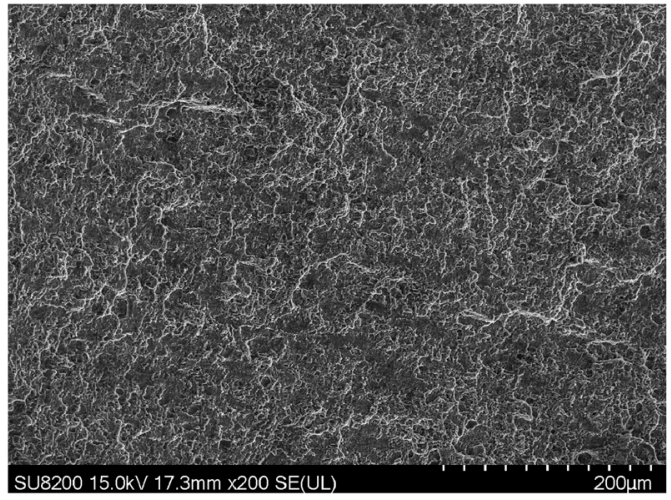

(a)

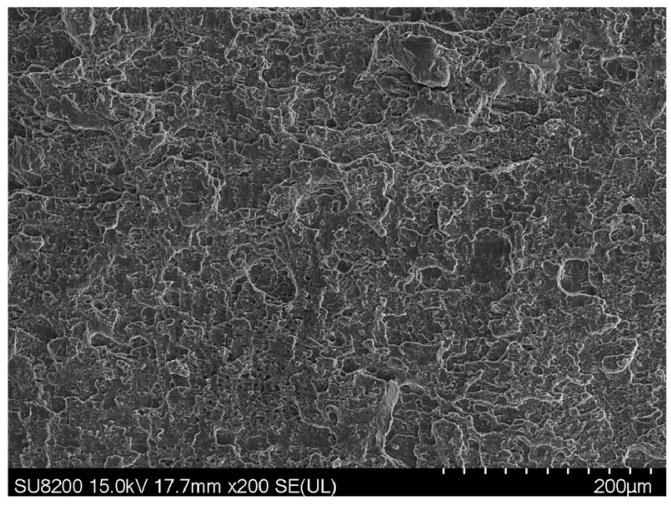

(c)

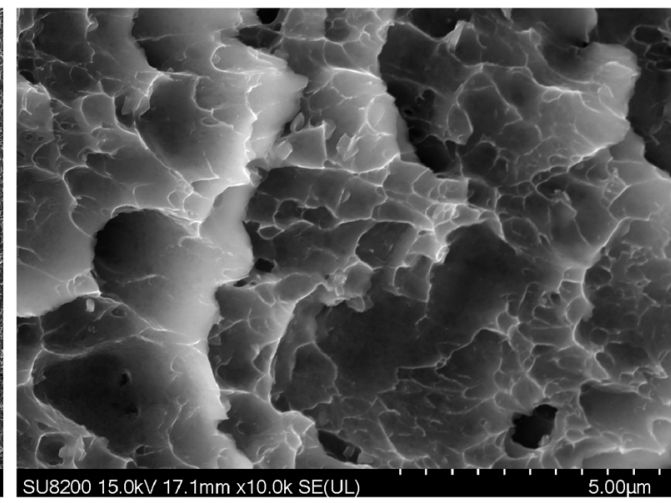

(b)

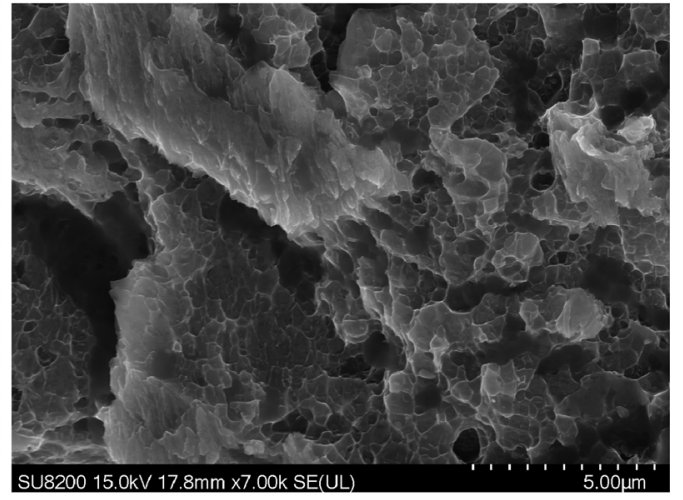

(d)

Fig. 14. Typical fractography micrographs observed by SEM after monotonic tensile tests: (a) sample F1 with a fracture in the middle of the joint, (b) higher magnification from (a), (c) sample G1 with a fracture on the advancing side in the TMAZ of AA2198, and (d) higher magnification from (c). 


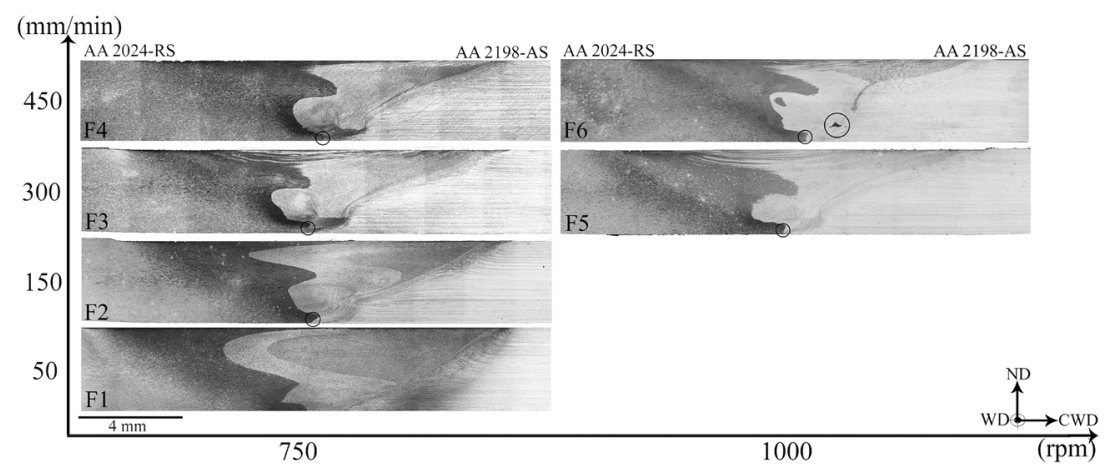

Fig. 15. Cross-sectional macrographs of joints produced by tool $\mathrm{F}$ with parameters of Table 3 . The tunneling defect was found in only joint F6 with the highest rational speed $(1000 \mathrm{rpm})$ and highest traverse speed $\left(450 \mathrm{~mm} \mathrm{~min}^{-1}\right)$.

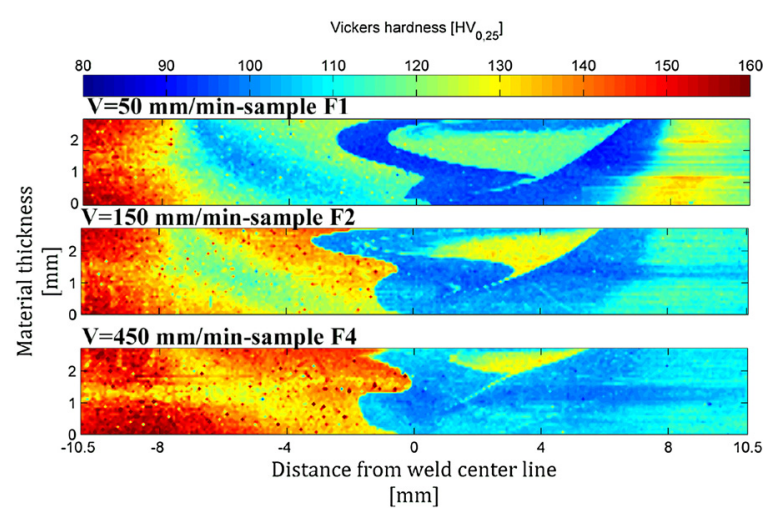

Fig. 16. Two-dimensional hardness map across the ND-CW section through the weld joints of samples F1, F2 and F4. A higher welding speed increases the general hardness of the joint.

Table 6

Microhardness of samples F1, F2 and F4 at different locations of the joint.

\begin{tabular}{lllll}
\hline Sample code & $\begin{array}{l}\text { Traverse speed } \\
\left(\mathrm{mm} \mathrm{min}^{-1}\right)\end{array}$ & $\begin{array}{l}\text { Nugget } \\
\left(\mathrm{HV}_{0.25}\right)\end{array}$ & $\begin{array}{l}\text { TMAZ of AA2198 } \\
\left(\mathrm{HV}_{0.25}\right)\end{array}$ & $\begin{array}{l}\text { TMAZ of AA2024 } \\
\left(\mathrm{HV}_{0.25}\right)\end{array}$ \\
\hline F1 & 50 & 91 & 93 & 108 \\
F2 & 150 & 100 & 101 & 120 \\
F4 & 450 & 108 & 109 & 133 \\
\hline
\end{tabular}

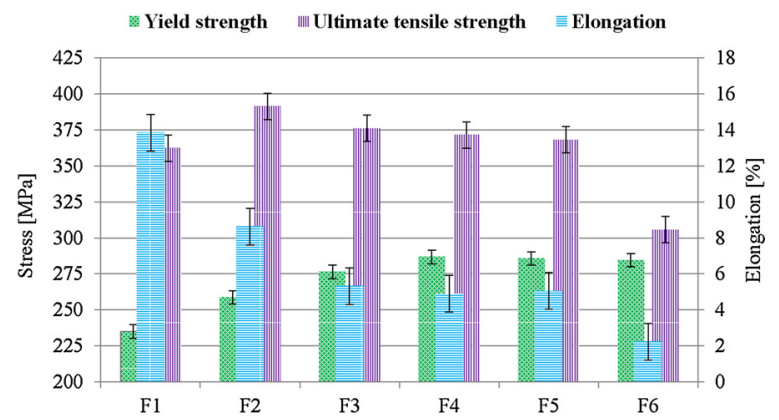

Fig. 17. Mechanical properties of FSW joints produced by tool $\mathrm{F}$ according to welding speed parameters in Table 3. Parameters $750 \mathrm{rpm}$ and $450 \mathrm{~mm} \mathrm{~min}^{-1}$ (sample F4) produced the joint with highest yield strength.

while the hardness of the nugget increased by about $17 \mathrm{HV}_{0.25}$ (Table 6).

\subsubsection{Mechanical response}

Increasing the traverse speed from 50 to $450 \mathrm{~mm} \mathrm{~min}^{-1}$ significantly increased the joint yield strength from 235 to $286 \mathrm{MPa}$, respectively (Fig. 17). This increase is consistent with a previous study on
AA2198-T8 [29]. While increasing the rotational speed for a given traverse speed (sample F5 vs. F3) did not show any significant effect on the mechanical properties of the joint, as reported in Ref. [32], it decreased significantly the UTS in sample F6 vs. F4 due to the presence of tunneling defect in the joint. The fracture locations of all samples were in the nugget area inside the AA2198 material. Results showed that the optimum rotational and traverse speeds to achieve a defect-free joint with the highest yield strength were $750 \mathrm{rpm}$ and $450 \mathrm{~mm} \mathrm{~min}^{-1}$, respectively, corresponding to the cold weld condition (the lowest $\mathrm{HI}$ index in Table 3). It should be noted that further improvement of joint strength could be investigated by applying post weld heat treatment, considering the fact that 3rd generation of Al-Li alloys are very responsive to age hardening. Also, using coolant such as air, water or liquid $\mathrm{CO}_{2}$, during welding may result in lower welding temperatures and higher joint mechanical properties. These two strategies could be considered for future works.

\section{Conclusions}

In the present study, different tool designs were tested for joining dissimilar aluminum alloys AA2024 and AA2198. The raised fan shoulder with a tapered cylindrical pin geometry that is easy to manufacture and provide good mechanical properties was selected to document the effect of welding speeds on joint mechanical properties. Even, if the selected geometry was found not to be the optimized for high production speed, relevant conclusions could be drawn:

- The weak regions of dissimilar joints AA2024/AA2198 are located on the AA2198 material in the nugget and on the TMAZ, justify that colder welding conditions may improve the joint mechanical properties.

- In fact, higher traverse speeds increase the hardness of the TMAZ/ HAZ and nugget, resulting better mechanical properties, however, a kissing bond defect was observed showing that the pin length should be increased for higher manufacturing conditions.

- The optimum welding speed parameters in the range of the tested parameters for achieving the highest yield strength corresponding the coldest weld are $750 \mathrm{rpm}$ and $450 \mathrm{~mm} \mathrm{~min}^{-1}$.

\section{Acknowledgments}

We would like to express our appreciation to Hossein Monajati for his help during this research. Without his valuable assistance, this work would not have been completed. A part of the research presented in this paper was financed by the Fonds de recherche du Qubec - Nature et technologies through the Aluminum Research Centre - REGAL. 


\section{References}

[1] Hasan MM, Ishak M, Rejab M. Influence of machine variables and tool profile on the tensile strength of dissimilar AA7075-AA6061 friction stir welds. Int J Adv Manuf Technol 2017;90(9-12):2605-15.

[2] KS AK, Karur AS, Chipli S, Singh A. Optimization of FSW parameters to improve the mechanical properties of AA2024-T351 similar joints using Taguchi method. J Mech Eng Autom 2015;5(3B):27-32.

[3] Durso G, Giardini C, Lorenzi S, Cabrini M, Pastore T. The influence of process parameters on mechanical properties and corrosion behaviour of friction stir welded aluminum joints. Procedia Eng 2017;207:591-6.

[4] Prasad NE, Gokhale A, Wanhill R. Aluminum-lithium alloys: processing, properties, and applications. Butterworth-Heinemann; 2013.

[5] Alexopoulos ND, Migklis E, Stylianos A, Myriounis DP. Fatigue behavior of the aeronautical Al-Li (2198) aluminum alloy under constant amplitude loading. Int J Fatigue 2013;56:95-105.

[6] Le Jolu T, Morgeneyer TF, Denquin A, Gourgues-Lorenzon A-F. Fatigue lifetime and tearing resistance of AA2198 Al-Cu-Li alloy friction stir welds: effect of defects. Int J Fatigue 2015;70:463-72.

[7] Kadlec M, Ruzek R, Novakova L. Mechanical behaviour of AA 7475 friction stir welds with the kissing bond defect. Int J Fatigue 2015;74:7-19.

[8] Le Jolu T, Morgeneyer TF, Denquin A, Sennour M, Laurent A, Besson J, et al. Microstructural characterization of internal welding defects and their effect on the tensile behavior of FSW joints of AA2198 Al-Cu-Li alloy. Metall Mater Trans A 2014;45(12):5531-44.

[9] Mishra RS, Ma Z. Friction stir welding and processing. Mater Sci Eng R: Rep 2005;50(1-2):1-78.

[10] Kumar K, Kailas SV. The role of friction stir welding tool on material flow and weld formation. Mater Sci Eng A 2008;485(1-2):367-74.

[11] Scialpi A, De Filippis L, Cavaliere P. Influence of shoulder geometry on microstructure and mechanical properties of friction stir welded 6082 aluminium alloy. Mater Des 2007;28(4):1124-9.

[12] Mohanty H, Mahapatra M, Kumar P, Biswas P, Mandal N. Effect of tool shoulder and pin probe profiles on friction stirred aluminum welds - a comparative study. J Mar Sci Appl 2012;11(2):200-7.

[13] Trueba Jr. L, Heredia G, Rybicki D, Johannes LB. Effect of tool shoulder features on defects and tensile properties of friction stir welded aluminum 6061-T6. J Mater Process Technol 2015;219:271-7.

[14] Kumar RA, Thansekhar M. Effects of tool pin profile and tool shoulder diameter on the tensile behaviour of friction stir welded joints of aluminium alloys. Advanced materials research vol. 984. Trans Tech Publ.; 2014. p. 586-91.

[15] Idris MH, Husin MS. Effect of friction stir welding pin shape on mechanical properties of AA6061 alloy weldment. Applied mechanics and materials vol. 465. Trans Tech Publ.; 2014. p. 1309-13.

[16] Reza-E-Rabby M, Reynolds AP. Effect of tool pin thread forms on friction stir weldability of different aluminum alloys. Procedia Eng 2014;90:637-42.

[17] Amini S, Amiri M. Pin axis effects on forces in friction stir welding process. Int J Adv Manuf Technol 2015;78(9-12):1795-801.

[18] Amirafshar A, Pouraliakbar H. Effect of tool pin design on the microstructural evolutions and tribological characteristics of friction stir processed structural steel. Measurement 2015;68:111-6.

[19] Jafarlou H, Jamalian HM, Eskandar MT. Investigation into the role of pin geometry on the corrosion behavior of multi-pass FSWed joints of Al5086 besides applying $\mathrm{Al}_{2} \mathrm{O}_{3}$ nanoparticles. J Manuf Process 2018;32:425-31.

[20] Kadian AK, Biswas P. Effect of tool pin profile on the material flow characteristics of AA6061. J Manuf Process 2017;26:382-92.

[21] Mustafa FF, Kadhym AH, Yahya HH. Tool geometries optimization for friction stir welding of AA6061-T6 aluminum alloy t-joint using Taguchi method to improve the mechanical behavior. J Manuf Sci Eng 2015;137(3):031018.

[22] Chen G, Li H, Wang G, Guo Z, Zhang S, Dai Q, et al. Effects of pin thread on the inprocess material flow behavior during friction stir welding: a computational fluid dynamics study. Int J Mach Tools Manuf 2018;124:12-21.

[23] Salari E, Jahazi M, Khodabandeh A, Ghasemi-Nanesa H. Influence of tool geometry and rotational speed on mechanical properties and defect formation in friction stir lap welded 5456 aluminum alloy sheets. Mater Des 2014:58:381-9.

[24] Ji S, Xing J, Yue Y, Ma Y, Zhang L, Gao S. Design of friction stir welding tool for avoiding root flaws. Materials 2013;6(12):5870-7.

[25] Kamble L, Soman S, Brahmankar P. Effect of tool design and process variables on mechanical properties and microstructure of AA6101-T6 alloy welded by friction stir welding. IOSR J Mech Civil Eng 2012. 2278-1684.

[26] Elangovan K, Balasubramanian V. Influences of tool pin profile and welding speed on the formation of friction stir processing zone in AA2219 aluminium alloy. $J$ Mater Process Technol 2008;200(1-3):163-75.

[27] Kim Y, Fujii H, Tsumura T, Komazaki T, Nakata K. Three defect types in friction stir welding of aluminum die casting alloy. Mater Sci Eng A 2006;415(1-2):250-4.

[28] Mastanaiah P, Sharma A, Reddy GM. Dissimilar friction stir welds in AA2219-AA5083 aluminium alloys: effect of process parameters on material intermixing, defect formation, and mechanical properties. Trans Indian Inst Met 2016;69(7):1397-415.

[29] Ma YE, Xia Z, Jiang R, Li W. Effect of welding parameters on mechanical and fatigue properties of friction stir welded 2198 T8 aluminum-lithium alloy joints. Eng Fract
Mech 2013;114:1-11.

[30] Jannet S, Mathews PK, Raja R. Optimization of process parameters of friction stir welded AA 5083-O aluminum alloy using response surface methodology. Bull Pol Acad Sci Tech Sci 2015;63(4):851-5.

[31] Hattel JH, Schmidt HNB, Tutum C. Thermomechanical modelling of friction stir welding. Proc. 8th Int. conference on trends in welding research 2009:1-10.

[32] Dubourg L, Amargier R, Jahazi M. Relationship between FSW parameters, hardness and tensile properties of 7075-T6 and 2098-T851 similar but welds. 2010.

[33] Venkateshkannan M, Rajkumar V, Sadeesh P, Arivazhagan N, Narayanan S, Ramkumar KD. Influences of tool geometry on metallurgical and mechanical properties of friction stir welded dissimilar AA 2024 and AA 5052. Procedia Eng 2014;75:154-8.

[34] Santhosh K, Aruri D. Practices in fsw welding and investigate effect of tool turning speed on tensile properties and microhardness of dissimilar aluminium alloys 2024 and 6061. Int J Mech Eng Technol 2017;8:165-72.

[35] Moradi MM, Aval HJ, Jamaati R, Amirkhanlou S, Ji S. Microstructure and texture evolution of friction stir welded dissimilar aluminum alloys: AA2024 and AA6061. J Manuf Process 2018;32:1-10.

[36] Kumar KA, Murigendrappa S, Kumar H. A bottom-up optimization approach for friction stir welding parameters of dissimilar Aa2024-T351 and Aa7075-T651 alloys. J Mater Eng Perform 2017;26(7):3347-67.

[37] Texier D, Zedan Y, Amoros T, Feulvarch E, Stinville J, Bocher P. Near-surface mechanical heterogeneities in a dissimilar aluminum alloys friction stir welded joint. Mater Des 2016;108:217-29.

[38] Robe H, Zedan Y, Chen J, Monajati H, Feulvarch E, Bocher P. Microstructural and mechanical characterization of a dissimilar friction stir welded butt joint made of AA2024-T3 and AA2198-T3. Mater Charact 2015;110:242-51.

[39] Radisavljevic I, Zivkovic A, Radovic N, Grabulov V. Influence of FSW parameters on formation quality and mechanical properties of Al 2024-T351 butt welded joints. Trans Nonferrous Met Soc China 2013;23(12):3525-39.

[40] Bitondo C, Prisco U, Squilace A, Buonadonna P, Dionoro G. Friction-stir welding of AA 2198 butt joints: mechanical characterization of the process and of the welds through DOE analysis. Int J Adv Manuf Technol 2011;53(5-8):505-16.

[41] Kasman Ş. Effects of FSW parameters and pin geometry on the weldability of EN AW 2024 alloy. Mater Test 2016;58(7-8):694-701.

[42] Bitondo C, Prisco U, Squillace A, Giorleo G, Buonadonna P, Dionoro G, et al. Friction stir welding of AA2198-T3 butt joints for aeronautical applications. Int J Mater Form 2010;3(1):1079-82.

[43] Bussu G, Irving P. The role of residual stress and heat affected zone properties on fatigue crack propagation in friction stir welded 2024-t351 aluminium joints. Int J Fatigue 2003;25(1):77-88.

[44] Chen J, Madi Y, Morgeneyer TF, Besson J. Plastic flow and ductile rupture of a 2198 Al-Cu-Li aluminum alloy. Comput Mater Sci 2011;50(4):1365-71.

[45] Zhang Y, Cao X, Larose S, Wanjara P. Review of tools for friction stir welding and processing. Can Metall Q 2012;51(3):250-61.

[46] Meilinger Á, Török I. The importance of friction stir welding tool. Prod Process Syst 2013;6(1):25-34.

[47] Dixit V, Mishra R, Lederich R, Talwar R. Influence of process parameters on microstructural evolution and mechanical properties in friction stirred Al-2024 (T3) alloy. Sci Technol Weld Join 2009;14(4):346-55.

[48] Arbegast W. Hot deformation of aluminum alloys III. Warrendale, PA: TMS; 2003. p. 313-27.

[49] Bridier F, Stinville JC, Vanderesse N, Villechaise P, Bocher P. Microscopic strain and crystal rotation measurement within metallurgical grains. Key engineering materials vol. 592. Trans Tech Publ.; 2014. p. 493-6.

[50] Seidel T, Reynolds AP. Visualization of the material flow in AA2195 friction-stir welds using a marker insert technique. Metall Mater Trans A 2001;32(11):2879-84.

[51] Shi L, Wu C. Transient model of heat transfer and material flow at different stages of friction stir welding process. J Manuf Process 2017;25:323-39.

[52] Gadakh VS, Adepu K. Heat generation model for taper cylindrical pin profile in FSW. J Mater Res Technol 2013;2(4):370-5.

[53] Bousquet E, Poulon-Quintin A, Puiggali M, Devos O, Touzet M. Relationship between microstructure, microhardness and corrosion sensitivity of an AA 2024-T3 friction stir welded joint. Corros Sci 2011;53(9):3026-34.

[54] Cavaliere P, Cabibbo M, Panella F, Squillace A. 2198 Al-Li plates joined by friction stir welding: mechanical and microstructural behavior. Mater Des 2009;30(9):3622-31.

[55] Ringer S, Muddle B, Polmear I. Effects of cold work on precipitation in $\mathrm{Al}-\mathrm{Cu}-\mathrm{Mg}-(\mathrm{Ag})$ and $\mathrm{Al}-\mathrm{Cu}-\mathrm{Li}-(\mathrm{Mg}-\mathrm{Ag})$ alloys. Metall Mater Trans A 1995;26(7):1659-71.

[56] Dorin T, Deschamps A, De Geuser F, Sigli C. Quantification and modelling of the microstructure/strength relationship by tailoring the morphological parameters of the T1 phase in an Al-Cu-Li alloy. Acta Mater 2014;75:134-46.

[57] Dorin T, Deschamps A, De Geuser F, Lefebvre W, Sigli C. Quantitative description of the $\mathrm{T} 1$ formation kinetics in an Al-Cu-Li alloy using differential scanning calorimetry small-angle X-ray scattering and transmission electron microscopy. Philos Mag 2014;94(10):1012-30.

[58] Genevois C, Deschamps A, Denquin A, Doisneau-Cottignies B. Quantitative investigation of precipitation and mechanical behaviour for AA2024 friction stir welds. Acta Mater 2005;53(8):2447-58. 